\title{
Abordagem transdisciplinar dos Parâmetros Curriculares Nacionais de Química: 0 caso das Geociências
}

\author{
Sidnei de Lima Júnior \\ Mestrando do Programa em Ensino e História das Ciências da Terra, \\ Instituto de Geociências, Unicamp, Campinas, SP. \\ sidnei.junior20@etec.sp.gov.br \\ Alfredo Borges De-Campos \\ Instituto de Geociências, Unicamp, Campinas, SP. \\ acampos@ige.unicamp.br \\ Cleonice Rocha \\ Depto. Matemática e Física, PUCGoiás, Goiânia, GO e professora \\ visitante no Instituto de Geociências, Unicamp, Campinas, \\ SP.rcleonice@gmail.com
}

\begin{abstract}
TRANSDisCiplinaRITY OF THE BRAZILIAN NATIONAL CURRICULUM PARAMETERS OF CHEMISTRY: THE CONTRIBUTION OF EARTH SCIENCES. Earth Science based knowledge is important for understanding terrestrial phenomena besides providing training for citizenship and promoting environmental sustainability culture. These skills are addressed in the curriculum of fundamental education disciplines, among them Chemistry. The authors performed an analysis of narratives from the Brazilian National Curriculum Parameters of Chemistry, which allowed to find ten strips covering topics in Earth Sciences and to point out topics that can be considered in Chemistry curriculum development. This approach can contribute to meaningful learning in Chemistry which is provided by data treatment and correlations between subjects from geodynamics (Earth System). However, it is crucial the role of the teacher as facilitator of the discipline content because the contextualization of knowledge enables one to addressing the issues from a transdisciplinary perspective. Citation: Lima Jr. S.de, De-Campos A.B., Rocha C. 2014. Análise da inserção de conhecimentos em Geociências nos Parâmetros Curriculares Nacionais de Química. Terræ Didatica, 10(3):289-297. http://www.ige.unicamp.br/terraedidatica/.
\end{abstract}

KEYWORDS: Chemistry learning, Earth Sciences, contextualization, citizenship.

RESUMO Conhecimentos gerados pelas Geociências são importantes para a compreensão de fenômenos terrestres, além de proporcionar formação para a cidadania e colaborar para a promoção de uma cultura de sustentabilidade ambiental. Estes conhecimentos são tratados nos currículos das disciplinas da área de ciências do ensino básico, dentre elas a Química. Por meio da análise de narrativas foram verificados dez trechos que abordam temas em Geociências propostos nos Parâmetros Curriculares Nacionais de Química no Brasil e apontados os tópicos presentes nestes documentos que podem ser trabalhados na elaboração do currículo de Química. Essa abordagem pode contribuir para uma aprendizagem significativa em Química, propiciada pelo tratamento e correlação dos assuntos por meio das diversas geodinâmicas (Sistema Terra). Porém é fundamental o papel do professor como mediador destes conteúdos, já que a contextualização dos conhecimentos possibilita um tratamento dos assuntos de forma transdisciplinar.

PALAVRAS CHAVE: Ensino de Química, Geociências, contextualização, cidadania. 


\section{Introdução}

A Educação escolar básica no Brasil, que compreende o ensino fundamental e médio, visa preparar os indivíduos para o pleno exercício da cidadania e também para o mercado do trabalho, conforme preconiza as LDB - Leis de Diretrizes e Bases da Educação Nacional (Brasil 1996). Ainda de acordo com a LDB, o ensino médio tem como finalidade o aprimoramento do educando como ser humano, desenvolver sua formação autônoma intelectual embasada na ética com enfoque no desenvolvimento de competências e preparação para o mundo do trabalho.

A Química, sendo uma das disciplinas ministradas no ensino médio e que faz parte do escopo das Ciências da Natureza e suas Tecnologias e conforme o PCNEM (Brasil 2000) apresenta-se como meio instrumental que contribui para a formação humanista dos discentes, ampliando os horizontes culturais e a autonomia no exercício da cidadania, além de contribuir para o desenvolvimento de competências e habilidades para sua emancipação intelectual no convívio cotidiano e na vida profissional.

Esta formação humanista é discutida e defendida por vários autores da educação em ciências (Gil-Pérez e Carrascosa 1994, Cachapuz et al. 2000), onde estes propõem, dentre diversos fatores, um ensino de ciências que utilize de abordagens por meio de situações problema, a fim de alcançar o interesse dos alunos no tratamento e difusão de conhecimentos científicos. Entretanto, uma formação para a cidadania só é alcançada caso a Química se preocupe em problematizar as questões do cotidiano e do mundo em que vivemos (Santos e Schnetzler 2010, Zanon e Maldaner 2012, Santana e Silva 2014).

Segundo os Parâmetros Curriculares Nacionais Ensino Médio em Brasil (2000, p.98), “[...] apropriar-se dos conhecimentos da Física, da Química e da Biologia, e aplicar esses conhecimentos para explicar o funcionamento do mundo natural, planejar, executar e avaliar ações de intervenção na realidade natural" colabora para atingir uma formação cidadã, desde que estes conhecimentos sejam articulados em conjunto.

Uma forma de articulação dos conhecimentos científicos de forma integrada com a realidade e que haja interrelações entre vários campos do conhecimento é a adoção, por parte dos docentes de abordagens transdisciplinares. Segundo Santos (2008), a transdisciplinaridade figura como uma forma de abordar os conhecimentos com articulações múltiplas e que leva o aprendizado a ser encarado como uma atividade prazerosa, já que não fica contido em um único conjunto de conhecimentos disciplinares e sim, leva o docente juntamente com os alunos a atividades de articulações entre os saberes, antes estanques, e agora de forma interrelacionada. Conforme preconizado no trecho:

"A transdisciplinaridade maximiza a aprendizagem ao trabalhar com imagens e conceitos que mobilizam, conjuntamente, as dimensões mentais, emocionais e corporais, tecendo relações tanto horizontais como verticais do conhecimento. Ela cria situações de maior envolvimento dos alunos na construção de significados para si. Os alunos "constroem" conhecimentos, como diz Paulo Freire (1997). Trabalhar a educação com tal visão supera a mesmice do padrão educativo, encanta o aprender e resgata o prazer de aventurar-se no mundo das idéias" (Santos 2008, p.76).

Segundo Iribarry (2003), o primeiro documento oficial que demonstra o interesse da sociedade científica pela transdisciplinaridade foi a Declaração de Veneza ocorrida em 1986, que emergiu como o comunicado final do Colóquio "A ciência diante das fronteiras do conhecimento", seguido por outros documentos lançados no Congresso "Ciência e tradição: perspectivas transdisciplinares para o século XXI" ocorrido em Paris no ano de 1991, a Carta da Transdisciplinaridade, lançada no Convento de Arrábida, em Portugal no ano de 1994, além de um novo documento lançado no Congresso Internacional "Que universidade para o amanhã", ocorrido na Suíça e a Conferência "Evolução transdisciplinar da universidade: condição para o desenvolvimento sustentável”, ocorrida na Tailândia, ambas no ano de 1997. Onde, dentre as apresentações e discussões dirimidas nestes encontros, de acordo com Iribarry (2003) é salientado que a transdiciplinaridade tem como ambição, a unificação, em suas diferenças do objeto e do sujeito, e que o sujeito é o conhecedor e este faz parte integrante da natureza e do conhecimento.

Nessa perspectiva a Química pode levar a uma melhor compreensão do mundo possibilitando intervenções na realidade e ainda, com seus conceitos, métodos e linguagens próprias, propiciar uma construção histórica da realidade atual pelos docentes e discentes, relacionando os conhecimentos abordados ao desenvolvimento tecnológico e aos muitos aspectos da vida, conforme é enfatizado nas LDB 
para o ensino médio, nos Parâmetros Curriculares Nacionais, e nas orientações educacionais complementares (Brasil 1996, 2000, 2002).

Nos Parâmetros Curriculares Nacionais para o ensino médio os docentes são convidados a abordarem temas para o ensino de Química que sejam apresentados como uma forma dos alunos reconhecerem e compreenderem, de forma integrada e significativa, as transformações químicas que ocorrem nos diversos processos naturais e tecnológicos em diferentes contextos, encontrados na atmosfera, na litosfera, na biosfera e hidrosfera, e suas relações com os sistemas produtivos, industrial e agrícola.

Ainda de acordo com os Parâmetros Curriculares Nacionais, o aprendizado de Química no ensino médio deve:

“[...] possibilitar ao aluno a compreensão tanto dos processos químicos em si, quanto da construção de um conhecimento científico em estreita relação com as aplicações tecnológicas e suas implicações ambientais, sociais e econômicas" (Brasil 2000 p. 31).

Além dos benefícios no escopo social, econômico e ambiental, com nítida vantagem quando se é utilizada uma abordagem Ciência, Tecnologia, Sociedade e Ambiente, os conteúdos de Química em conjunto com outras disciplinas, comumente a Física, a Biologia, a Matemática e também outras disciplinas das áreas das Ciências Humanas, como a Geografia, Sociologia e História, propiciam correlações nas abordagens de assuntos cotidianos, na busca pelo letramento ou alfabetização científica pelos professores que atuam com este propósito durante o exercício profissional. A alfabetização científica ocorre por meio da aprendizagem de termos, conhecimentos e expressões, em geral desconhecidas pelos alunos, que os leva a uma reflexão e ordenação dos conhecimentos mais correlacionados com os eventos vivenciados na realidade de cada discente, emergindo assim potenciais significações e resignificações de conteúdos mediados no ensino formal e informal frente ao ambiente em que a sociedade está inserida (Santos e Schnetzler 1997, Cachapuz et al. 2005). Uma ferramenta didático-pedagógica útil para fomentar a alfabetização científica é a experimentação, onde a Química se destaca como disciplina importante na mediação e tratamento de conhecimentos técnicos, científicos e específicos no campo das ciências, e como facilitadora na abordagem destes fatores e conceitos por meio das atividades práticas experimentais (Giordan 1999, Lima Júnior 2004 e 2012, Guimarães 2009).

Para que esses objetivos formativos sejam atingidos, a escolha e a estruturação dos conteúdos são importantes. Os conteúdos a serem abordados devem atender os parâmetros curriculares e ainda, melhorar o ensino de Química, que conforme Brasil (2002), o conhecimento abordado em Química para o nível médio, muitas vezes limita-se a uma aprendizagem mecânica de definições e de leis isoladas, na memorização de fórmulas e equações, configurando assim um ensino desvinculado de uma real compreensão dos conteúdos lecionados. Conforme citado nos Parâmetros Curriculares Nacionais para o ensino médio (Brasil 2000), o ensino de um conteúdo abrangente relacionado ao cotidiano e aos problemas que afligem o mundo que cerca o aluno e o professor se estabelece como um cenário facilitador na mediação dos conhecimentos em Química durante as fases do ensino básico.

No contexto de um ensino que valoriza o universo da vivência do aluno e a compreensão dos fenômenos terrestres é que se inserem os temas em Geociências, os quais possuem abordagens interdisciplinares (no sentido de Piaget 2006) e são contempladas nas disciplinas de Química, Física, Biologia e Geografia ministradas no ensino básico (Brasil 2000, Toledo 2004).

Alvarez et al. (1992), Carneiro et al. (2004) e Toledo (2004) defendem a inclusão de temas mais integrais e abrangentes em Geociências que valorizam a dinâmica do ambiente terrestre como mediadores no ensino dos conteúdos de ciências, particularmente o de Química. Nessa mesma linha, outros autores ponderam que as abordagens de conteúdos de ciências pelo viés das Geociências podem contribuir significativamente para a compreensão dos conteúdos lecionados no ensino básico (Paschoale et al. 1981, Compiani 1990, Amaral 1991, Alvarez et al. 1992, Toledo 2004, Barbosa 2003, Carneiro et al. 2004 e 2007, Galvão e Finco 2009), inclusive delineando razões pelas quais a inserção da cultura geológica beneficiaria o ensino básico nacional (Alvarez et al. 1992, Carneiro et al. 2004). No conjunto de disciplinas que formam as Geociências, a Geologia aparece muitas vezes destacada por vários motivos, dentre eles por ser considerada uma ciência histórica da natureza, segundo concepção de Potapova (1968) e Frodeman (1995), que facilita o alcance dos objetivos da educação, por abranger e articular diversos aspectos da dinâmica do planeta. 
Tendo em vista as importantes contribuições que temas em Geociências podem trazer aos conteúdos de Química, contemplados nos Parâmetros Curriculares Nacionais de Química e voltados para a formação da cidadania, compreensão dos fenômenos na dinâmica terrestre e promoção da sustentabilidade ambiental, é que se insere esse estudo. Ao longo do artigo procura-se enfatizar a inserção dos conteúdos provenientes das Geociências no currículo de Química e as várias possibilidades geradas para uma abordagem destes conteúdos no ensino médio pelo viés das Geociências, como pressuposto para a promoção de uma aprendizagem mais significativa

De acordo com Moreira (1999), Novak e Gowin (1999), baseados nas propostas de Ausubel (1968) a aprendizagem significativa é um processo que utiliza dos conhecimentos prévios dos alunos, onde os docentes fazem uso destes, para estruturar suas abordagens na mediação dos conhecimentos. Guimarães (2009) expõe ainda, que a Química, por meio da experimentação, colabora para alcançar uma aprendizagem mais significativa, avaliando o que os alunos já sabem e então, direcionando os conhecimentos e o aprimoramento destes por meio de abordagens de conceitos em Química com o uso de atividades experimentais.

O presente estudo objetivou avaliar a inserção de conhecimentos em Geociências nos Parâmetros Curriculares Nacionais de Química (PCNEM). Objetivou-se ainda, demonstrar que as Geociências têm uma contribuição importante para se atingir as metas do ensino médio expostos nos PCNEM e, num âmbito mais geral, estas podem contribuir expressivamente para o alcance da formação para cidadania, compreensão dos fenômenos terrestres e sustentabilidade ambiental do planeta (conforme Bruntland 1987), além de propiciar aos professores uma abordagem de conteúdos curriculares em Química contextualizados no Sistema Terra (Teixeira et al. 2009).

\section{Metodologia}

Para a realização deste estudo utilizaram-se os documentos contidos nos Parâmetros Curriculares Nacionais de Química (PCNEM, Brasil 2000) e o referencial teórico em Geociências proposto por Teixeira et al. (2009).

A partir da leitura analítica dos conteúdos expressos no PCNEM, foi utilizado o processo de análise de narrativas (Galvão 2005), onde foram selecionados os trechos relacionados a temas geocientíficos. Para a escolha dos trechos utilizou-se de palavras-chave que remetem a conotações com o meio natural em que vivemos, como por exemplo: clima, hidrosfera, litosfera, ciclos biogeoquímicos.

Após escolha e análise dos trechos fez-se uma discussão, apresentado ao longo do texto, sobre a inserção dos conhecimentos em Geociências, por meio das propostas de abordagem de conteúdos ministrados no currículo de Química do Ensino Médio no Brasil.

\section{Resultados e discussão}

De acordo com a análise elaborada neste trabalho foram encontrados dez trechos referentes a temáticas que remetem a Geociências.

Os PCNEM, especificamente no que se refere aos conteúdos de Química, apontam alguns assuntos na forma de temas e discussões que procuram correlacionar conteúdos propostos para a formação do currículo de Química com conhecimentos em Geociências.

Estes trechos são apontados como mediadores de conhecimentos em Química pelo viés gerado por meio dos vários temas trabalhados em Geociências, sendo o primeiro descrito a seguir:

"Estas correlações podem ser exemplificadas no caso do enxofre elementar: sua distribuição no globo terrestre segue uma linha que está determinada pelas regiões vulcânicas; sua obtenção se baseia no seu relativamente baixo ponto de fusão e suas propriedades químicas o tornam material imprescindível para a indústria química" (Brasil 2000, p.30).

Considerando este primeiro trecho extraído do PCNEM, são evidentes as possibilidades de abordagem de conteúdos relacionados ao elemento químico enxofre frente à sua interação com o meio natural (regiões vulcânicas), onde há possibilidades de trabalhar conteúdos que envolvem as inter e intrapartículas deste elemento, a polaridade nas ligações químicas e nas moléculas, os diferentes tipos de ligações químicas entre átomos do mesmo elemento ou com outros elementos químicos e suas relações com diferentes pontos de fusão e ebulição. A abordagem desses conceitos químicos pode ser feita de forma contextualizada considerando o que seja um ambiente vulcânico, as rochas e minerais associados a este. 
A classificação e avaliação de métodos de separação no sistema produtivo do enxofre quando presente na Natureza na forma de sais ou óxidos, portanto na forma de minerais, levam a trabalhar assuntos como transformações químicas, proporção e conservação das massas e reagentes, bem como realizar cálculos estequiométricos e estimativas para interpretar a cinética e o equilíbrio químico das reações envolvidas nestes processos. As possibilidades de aplicações tecnológicas e usos cotidianos do enxofre em diferentes materiais podem ser explanadas enfatizando os aspectos e impactos sociais, tecnológicos, econômicos e ambientais inerentes ao seu uso e descarte.

Em outro momento a correlação entre Química e Geociências é evidenciada na busca para se entender algumas geodinâmicas terrestres pelo ser humano, como no trecho a seguir:

"O ser humano, na luta pela sua sobrevivência, sempre teve a necessidade de conhecer, entender e utilizar o mundo que o cerca. Nesse processo, obteve alimentos por coleta de vegetais, caça e pesca; descobriu abrigos, protegendo-se contra animais e intempéries; descobriu a força dos ventos e das águas, o fogo e a periodicidade do clima nas estações do ano" (Brasil 2000, p.31).

As possibilidades de uma abordagem transdisciplinar, especificamente dentro dos conteúdos de Química, pelo respectivo docente da área durante suas aulas, tendo como eixo temas tratados pelas Geociências (água, vento, clima) são claramente propostas no parágrafo anterior. No contexto do ensino de Química, pode se abordar conteúdos como as funções inorgânicas e orgânicas presentes nos nutrientes e composição dos alimentos, a termoquímica e cinética química podem ser exploradas por meio do tratamento de conhecimentos em energia e reações envolvidas em processos de combustão e apontados pela descoberta do fogo nos PCNEM de Química. Estimulando ainda, as possibilidades da interdisciplinaridade em conjunto com docentes de disciplinas como a Geografia, História, Sociologia e Biologia por meio do tratamento de assuntos relacionados a fatos cotidianos dos seres humanos durante a formação das primeiras civilizações e a luta pela sobrevivência em épocas mais remotas da humanidade.

A Química se destaca como uma ciência com suas raízes históricas no processo de aquisição do conhecimento sistematizado. Assim, a Química tornou-se um dos meios de interpretação e utilização dos recursos do mundo físico, por consequência com fortes elos com as Geociências, como tratado abaixo:

"É óbvio que o mundo físico é um sistema global complexo, formado por subsistemas que, interagindoe se relacionando, interferem nos processos sociais, econômicos, políticos, científicos, tecnológicos, éticos e culturais. O conhecimento especializado, o conhecimento químico isolado, é necessário, mas não suficiente para o entendimento do mundo físico, pois não é capaz de estabelecer explícita e constantemente, por si só, as interações com outros subsistemas. Isso é verdade não só na Química. Por exemplo, para a compreensão da respiração humana, não basta o conhecimento do aparelho respiratório. É necessário que se conheçam conceitos como pressão atmosférica, dissolução e transporte de gases, combustão, capilaridade. $\mathrm{Na}$ interpretação do mundo através das ferramentas da Química, é essencial que se explicite seu caráter dinâmico" (Brasil 2000, p.31).

Deste modo as interações do homem com o meio, especificamente com os materiais disponíveis na Natureza, levam à compreensão da sua participação na geodinâmica terrestre (Sistema Terra). Por exemplo, a total dependência do oxigênio para a sobrevivência dos seres humanos. Neste contexto, podem-se trabalhar conhecimentos não só sobre o elemento químico oxigênio, mas também conhecimentos inerentes a outros elementos encontrados, na atmosfera terrestre. A disposição do oxigênio na composição dos minerais e rochas na forma de óxidos, ácidos, sais, hidróxidos e peróxidos, disponibilizada ao longo do tempo nas diversas etapas dos ciclos biogeoquímicos dos elementos. A influência do oxigênio na forma de hidróxidos no equilíbrio ácido base na natureza, as reações químicas envolvidas na fixação destes na formação mineral e das rochas. A interpretação da sua influência em processos oxidativos naturais e antrópicos, bem como a extração de gases da atmosfera utilizando de processos de liquefação e destilação fracionada, salientando as variáveis envolvidas, como pressão e temperatura e as inúmeras utilizações pela sociedade.

A indicação da abordagem desenvolvida pelas 
Geociências para tratar determinados assuntos mediados durante o ensino de Química é enfatizada ainda em fatos e eventos do cotidiano social dos alunos, com vistas à contextualização dos conteúdos, sem se prender a temas específicos não inter-relacionados e sim incentivando a inter-relação dos assuntos como forma de flexibilizar e interagir com o mundo, conforme o trecho abaixo:

"Os conteúdos nessa fase devem ser abordados a partir de temas que permitam a contextualização do conhecimento. Nesse sentido, podem ser explorados, por exemplo, temas como metalurgia, solos e sua fertilização, combustíveis e combustão, obtenção, conservação e uso dos alimentos, chuva ácida, tratamento de água etc. Não se pretende que esses temas sejam esgotados, mesmo porque as inter-relações conceituais e factuais podem ser muitas e complexas. Esses temas, mais do que fontes desencadeadoras de conhecimentos específicos, devem ser vistos como instrumentos para uma primeira leitura integrada do mundo com as lentes da Química." (Brasil 2000, p.34)

Nesse contexto, ao utilizar a água como tema, vários conteúdos de Química podem ser explorados como: as relações quantitativas e qualitativas envolvidas nas transformações químicas em soluções, solubilidade de gases em água levam ao entendimento da adoção de determinados tipos de tratamento de água. A abordagem sobre diferentes unidades de concentração de constituintes na água, como premissa para avaliar a qualidade das águas são tópicos enfatizados pelo trecho anterior do PCNEM. A utilização de cálculos de entalpia para balanços energéticos das rupturas de ligações químicas entre elementos e substâncias combustíveis e a reatividade dos metais encontrados no solo e nas rochas. A explanação sobre as reações de oxirredução entre metais e outros elementos levam à compreensão dos alunos sobre a fertilidade de solos e manutenção destes para as diversas culturas agrícolas que levam à obtenção de alimentos e congêneres.

Também nos documentos analisados foi possível constatar que há uma organização de conteúdos de cunho científico-tecnológico relacionados ao ambiente em que vivemos, portanto com fortes vínculos com as questões tratadas pelas Geociências, de acordo com o trecho abaixo:
"Na luta pela sua sobrevivência, o ser humano extraiu e sintetizou materiais a partir da biosfera, hidrosfera, litosfera e atmosfera. Nesses processos, ele afetou seu ambiente, modificando-o e degradando-o. Dessa maneira, os conteúdos a serem abordados nessa fase devem se referir aos materiais extraídos e sintetizados pelo ser humano, bem como aos materiais introduzidos no ambiente em decorrência dos processos de fabricação e de uso. Devem abordar as implicações econômicas, sociais e políticas dos sistemas produtivos agrícolas e industrial" (Brasil 2000, p.35).

O trecho selecionado do PCNEM de Química enfatiza a dependência do homem à exploração dos recursos naturais disponibilizados no meio ambiente e que por meio de reações químicas, físicas ou físico-químicas são capazes de obter materiais utilizados como matérias primas ou insumos para a fabricação de bens de consumo. Novamente, conteúdos de termoquímica e cinética química podem ser explorados como meio de obtenção destes materiais pela sociedade atual, além das possibilidades de se trabalhar conceitos de equilíbrio químico nestas reações com ênfase na degradação ambiental causada com a exploração exacerbada dos recursos naturais pela sociedade atual.

Ainda, o documento utiliza exemplos para a efetivação do exercício de abordar conhecimentos em Química utilizando-se o meio ambiente e processos terrestres (Sistema Terra) envolvidos neste, conforme segue abaixo:

"Para se compreender, por exemplo, a interação do ser humano com a atmosfera do ponto de vista da Química, é preciso que se entenda como a atmosfera se formou e permitiu a manutenção de vida na Terra, bem como se tornou fonte de materiais úteis à sobrevivência humana. Pode-se conhecer como o homem transformou o nitrogênio em substâncias para os mais variados usos, como fertilizantes na agricultura e intermediários na indústria química, a exemplo do ácido nítrico e da amônia. Pode-se também procurar entender e avaliar como esses processos de transformação e os usos dos materiais produzidos modificaram o ambiente, na poluição atmosférica, e qual o papel do cidadão e da sociedade 
frente às modificações ambientais. Ainda, a compreensão do ciclo biogeoquímico do nitrogênio pode contribuir para a construção de uma visão integrada dos processos que ocorrem na natureza" (Brasil 2000, p. 35).

Neste trecho do PCNEM, estimula-se a abordagem de assuntos como equilíbrio e cinética química de reações, os fatores interferentes, a energia de ativação das reações, além da estequiometria envolvida nas reações de obtenção do nitrogênio e de produtos que o utilizam em seus respectivos processos. A utilização do nitrogênio pela sociedade, a presença deste elemento em alimentos e outros compostos naturais podem levar à compreensão dos alunos quanto à necessidade de preservação do meio, onde resíduos que contêm nitrogênio em determinados estados físicos e concentração podem levar à intensificação de chuvas ácidas, eutrofização de corpos d'água, dentre outras consequências.

Também nos documentos aparece a preocupação com a desmitificação da Química como vilã poluidora do meio ambiente e nestes se propõe que os conteúdos ensinados em Química devam estar a serviço da sustentabilidade ambiental, a qual é evidenciada no trecho a seguir:

"Esses conhecimentos exigem, entre outras, competências e habilidades de reconhecer o papel da Química no sistema produtivo, reconhecer as relações entre desenvolvimento científico e tecnológico e aspectos sociopolítico-econômicos, como nas relações entre produção de fertilizantes, produtividade agrícola e poluição ambiental, e de reconhecer limites éticos e morais envolvidos no desenvolvimento da Química e da tecnologia, apontando a importância do emprego de processos industriais ambientalmente limpos, controle e monitoramento da poluição, divulgação pública de índices de qualidade ambiental" (Brasil 2000, p.35).

Salienta-se a preocupação do PCNEM na formação da cidadania quando a Química é tratada como facilitadora na compreensão de questões ambientais, ou seja, como fonte imprescindível de conhecimentos e técnicas voltados para a compreensão e resolução de problemas relacionados à contaminação e utilização em demasia de determinados recursos naturais. Enfatizam-se assim as possibilidades que a Química oferece para a criação de novos produtos, otimização de processos e utilização de matérias primas de maneira sustentável.

Em se tratando de buscar a interdisciplinaridade no tratamento de conteúdos em Química, algumas abordagens realizadas pelas Geociências também são mencionadas nos documentos como facilitadoras para o alcance da interdisciplinaridade, conforme exposto a seguir:

“(...), os estudos a partir da atmosfera, hidrosfera, litosfera e biosfera são muito apropriados para aprofundar a interdisciplinaridade, pois o entendimento da participação de cada uma dessas partes no conjunto e a do próprio conjunto requerem não só o conhecimento específico, mas fundamentalmente o entendimento dos resultados das interações entre os conhecimentos químicos e os conhecimentos físicos, biológicos e geológicos" (Brasil 2000, p.36).

A Química também é capaz de levar os alunos a reconhecer e compreender a interação e o equilíbrio entre os diferentes processos que ocorrem simultaneamente ou não na natureza, por meio das reações químicas envolvidas, as substâncias participantes nos balanços energéticos e de massa dos subsistemas na dinâmica terrestre.

A complexidade dos fatores envolvidos na pesquisa e explotação mineral, área tradicionalmente tratada pelas Geociências, surge também nos documentos como tema gerador de discussões e mediação da Química, de acordo com o trecho abaixo:

"Para que se possa ter uma visão mais específica, apresenta-se a metalurgia como um exemplo de abordagem de temas, objetivando o desenvolvimento das competências e habilidades que levam ao fio condutor proposto. Pode-se, no primeiro momento, focalizar o problema da mineração e metalurgia do ferro no Brasil, visando ao desenvolvimento das competências e habilidades dentro do campo da percepção sociocultural e histórica. Considerando as habilidades e competências propostas em Química, o aluno aprende a ler e a representar as transformações químicas que ocorrem no alto-forno. Analisando o boletim de produção de uma siderúrgica, podese entender o rendimento de um processo industrial e associá-lo ao rendimento baseado na estequiometria. Visando à generalização, esse entendimento pode ser estendido a outras transformações químicas, sem, no entanto, 
esgotar o assunto.(...). A metalurgia pode ainda ser examinada no contexto de um estudo mais amplo da litosfera. Assim, estudamse fontes naturais de minérios dos quais se extraem os diferentes metais, os processos químicos envolvidos nessas transformações, as implicações sociais, econômicas e ambientais decorrentes da obtenção e do uso desses metais" (Brasil 2000, p. 37).

Considerando-se o trecho apontado é possível explorar as características e propriedades dos materiais, enfocando os elementos mais comuns encontrados nos minerais como fontes para obtenção de matérias primas destinadas ao beneficiamento e produção de ligas metálicas. A abordagem de ligações químicas, arranjos cristalinos, reações químicas de oxidação e redução, cálculos de rendimentos e reagentes em excesso em reações comuns utilizadas na siderurgia e metalurgia, e energia envolvida nos processos industriais produtivos são exemplos de conteúdos que podem ser abordados pelos docentes de Química de nível médio.

Por fim, os documentos do PCNEM lembram a importância de explorar assuntos relacionados à obtenção de energia, extensivamente tratados pelas Geociências, bem como fatores socioeconômicos e ambientais envolvidos na exploração de fontes de energia não renováveis, de acordo com o trecho:

“Outros temas podem ser enfocados dessa
mesma maneira. Por exemplo, o tema
combustível pode, num primeiro momento,
ser estudado em termos do entendimento das
reações de combustão, tanto em seus aspectos
qualitativos, quantitativos, macroscópicos
e microscópicos. Num segundo momento,
deve-se procurar entender a problemática
dos combustíveis, considerando-se as fontes
renováveis e não renováveis, litosfera e
biosfera, os problemas ambientais decorrentes
do uso dos combustíveis, as relações
entre desenvolvimento socioeconômico e
disponibilidades de energia” (Brasil 2000 ,
p.37).

Os trechos selecionados podem ainda ser abordados na forma de problematização ou de forma indagadora utilizando dos temas em Geociências explicitados nesta análise, a fim de proporcionar um melhor tratamento dos conhecimentos de Química na abordagem dos docentes durante o exercício da profissão.

\section{Conclusão}

A análise realizada nos documentos do PCNEM possibilitou identificar algumas contribuições que as Geociências podem oferecer para a abordagem e sistematização de currículos em Química ministrados para alunos do ensino médio. Identificaram-se alternativas de contextualização do ensino dos conteúdos de Química que ajudam, em paralelo, a desenvolver abordagens didático-pedagógicas que proporcionem uma aprendizagem mais significativa de conceitos por parte dos discentes.

A análise em nenhum momento procurou extirpar currículos e formas de abordagem de conteúdos específicos por parte dos docentes no campo da Química ou das diversas ciências, mas levantar as possibilidades que os PCNEM oferecem para se tratar de forma mais contextualizada temas relacionados às Geociências.

Embora cada docente possa sentir-se livre para adotar tais posturas, diante das várias propostas de abordagem em Química que os PCNEM oferecem, salienta-se que o estudo dos diferentes processos e subprocessos dinâmicos naturais da Terra tipicamente envolvidos nas Geociências ajudam a atingir as metas do ensino médio expostos nos PCNEM. Em um cenário mais amplo, o conhecimento assim desenvolvido pode contribuir efetivamente para uma formação voltada para a construção de cidadania, compreensão dos fenômenos terrestres e sustentabilidade ambiental do planeta.

\section{Referências bibliográficas}

Alvarez Suárez R., Berjillos Ruiz P., Garcia de La Torre E., Melero Vara J., Pedrinaci Rodriguez E., Sequeiros Sanromán L. 1992. Treinta razones para aprender más Geología en la educación secundaria. In:Simposio Enseñanza de la Geología, 7, Santiago de Compostela, 1992. Actas... Santiago de Compostela: AEPECT, p. 231-240.

Amaral I.A.do. 1991. Ambiente, educação ambiental e ensino de Ciências. In: M.M.S.de Lima, N.M.M. Kiouranis, R.C.E.G. Gonçalves, S.M.A. Alencar eds. 1991. Ciências na escola de $1^{\circ}$ Grau. Textos de apoio à proposta curricular. São Paulo: Secret. Est. Educação, Coord. Estudos e Normas Pedagógicas. p. 39-62.

Ausubel D.P. 1968. Educational Psycology: A cognitive View. New York. Holt, Rinehart and Winston, 1968.

Barbosa R. 2003. Projeto Geo-Escola: recursos computacionais de apoio ao ensino de geociências nos níveis fundamental e médio. Campinas. Inst. Geoc. 
Unicamp. 105p. (Dissertação Mestr.).

Brasil. 1996. Lei n. 9394. Diretrizes e bases da educação nacional, promulgada em 20/12/1996. Brasília: Editora do Brasil. 31p.

Brasil. 2000. Ministério da Educação MEC. Secretaria de Educação Média e Tecnológica. Parâmetros Curriculares Nacionais para o Ensino Médio. Brasília: MEC/Semtec. 364p.

Brasil. 2002. PCN + Ensino Médio: orientações educacionais complementares aos Parâmetros Curriculares Nacionais: Ciências da Natureza, Matemática e suas Tecnologias. Brasília: MEC/ Semtec. 144 p.

Bruntland G. ed. 1987. Our Common Future: The World Commission on Environment and Development, Oxford: Oxford University Press.

Cachapuz A., Gil-Perez D., Carvalho A.M., Praia J., Vilches A. 2005. A necessária renovação do ensino das ciências. São Paulo: Cortez. 263p.

Carneiro C.D.R., Barbosa, R., Piranha J.M. 2007. Bases teóricas do projeto Geo-Escola: uso de computador para ensino de Geociências. Rev. Bras. Geoc. 37(1):90-100.

Carneiro C.D.R., Toledo M.C.M.de, Almeida F.F.M.de. 2004. Dez motivos para a inclusão de temas de Geologia na Educação Básica. Rev. Bras. Geoc., 34(4):553-560.

Compiani M. 1990. A geologia pra que te quero no ensino de ciências. Educ. E Soc., 36:100-117.

Freire P. 1997. Pedagogia da autonomia: saberes necessários à prática educativa. São Paulo, Paz e Terra.

Frodeman R. 1995. Geological reasoning: geology as an interpretive and historical science. GSA Bulletin, 107(8):960-968.

Galvão C. 2005. Narrativas em educação. Ciência E Educação. 11(2):327-345.

Galvão D.M., Finco G. 2009. Geociências no Ensino Médio: aprendendo para a cidadania. In: VII Encontro Nacional de Pesquisa em Ensino de Ciências: Florianópolis, 2009. Anais... Florianópolis: 9p. URL: http://posgrad.fae.ufmg.br/pos$\mathrm{grad} /$ viienpec/pdfs/1437.pdf. Acesso 15.09.2014.

Gil-Perez D., Carrascosa, J. 1994. Bringing Pupil's Learning Closer to a Scientific Construction ok Knowledge: A permanent Feature in Innovations in Science Teaching. Science Education, 78(3):301-315

Giordan M.1999 O papel da experimentação no ensino de ciências. Química Nova na Escola, 10:43-49.

Guimarães C.C. 2009. Experimentação no ensino de Química: Caminhos e Descaminhos Rumo à Aprendizagem Significativa. Química Nova na
Escola, 31(3):198-202.

Iribarry I.N. 2003. Aproximações sobre a transdiciplinaridade: Algumas linhas Históricas, Fundamentos e Princípios. Aplicados ao Trabalho em equipe. Rio Grande do Sul: UFRGS, Psicologia: Reflexão e crítica, 16(3):483-490.

Lima Jr. S. 2004. A abordagem de atividades experimentais em livros didáticos de Química. In: Enc. Nac. Ens. Química, 12, Goiânia, 2004. Anais... Goiânia: UFG, 2004.

Lima Jr. S. 2012. A utilização da experimentação em química de nível médio: contextualização de conteúdos de Química. In: Enc. Nac. Ens. Química, 16, Salvador, 2012. Anais... Salvador: URL: www.portalseer.ufba.br/index.php/anaiseneq2012/index.

Moreira M.A. 1999. Aprendizagem significativa. Brasília: Ed. UnB, 1999.

Novak J.D. Gowin D.B. 1999. Aprender a aprender. 2 ed. Lisboa: Plátano ed. técn.

Paschoale C., Freitas H.C.L.de, Fracalanza H., Amaral I.A.do, Tessler M.G. 1981. A geologia e a escola de $1^{\circ}$ e $2^{\circ}$ graus. In: Simpósio Nacional sobre o Ensino de Geologia no Brasil, 1, Belo Horizonte. Anais..., Belo Horizonte, SBG. v. 1, p. 157-167.

Piaget J. 2006. Metodologia das relações interdisciplinares. In: Pombo, Olga, Guimarães, Henrique M., Levy, Teresa orgs. 2006. Interdisciplinaridade: Antologia. Porto: Campo das Letras Eds. p.59-68.

Potapova M.S. 1968. Geology as an historical science of nature. In: Interaction of sciences in the study of the Earth. Moscow: Progress Publisher. p.117126. Tradução: Potapova M.S. 2008. Geologia como uma ciência histórica da natureza. Terrce Didatica, 3(1):86-90. URL: http://www.ige.unicamp. br/terraedidatica/. Acesso 16.09.2014.

Santana E.M., Silva E.L. orgs. 2014. Tópicos em ensino de Química. São Carlos, Pedro \& João Eds. 252p.

Santos W.L.P., Schnetzler R.P. 2010. Educação em química: compromisso com a cidadania. 4 ed., Ijuí: Ed. Unijuí. 159p.

Teixeira W. Fairchild T.R, Toledo M.C.M, Taioli F. 2009. Decifrando a Terra. 2 ed. São Paulo: Cia. Ed. Nacional. 623p.

Toledo M.C.M. 2004. Geociências no Ensino Médio Brasileiro. Análise dos Parâmetros Curriculares Nacionais. São Paulo, Revista Geologia USP. Publ. Esp., 3:33-34.

Zanon L.B., Maldaner O.T. orgs. 2012. Fundamentos e Propostas de Ensino de Química para a Educação Básica no Brasil. Ijuí, Ed. Unijuí. 224p. 